\title{
ADDENDUM
}

\section{Why nonconventional materials are answers for sustainable agriculture - ADDENDUM}

doi: https://doi.org/10.1557/mre.2019.7

The following footnote should be included in this article [1]:

This paper was commissioned and accepted for publication by David Cahen, who served as Editor-in-Chief of this journal from 2014-2018.
Caue Ribeiro and Marcelo Carmo

REFERENCE:

1. Ribeiro C., \& Carmo M. (2019). Why nonconventional materials are answers for sustainable agriculture. MRS Energy \& Sustainability, 6, E9 Cambridge University Press. 